\title{
EVENT-DRIVEN OBSERVATIONS AND COMPREHENSIVE EVALUATION FOR NATURAL DISASTER ASSESSMENT IN CHINA
}

\author{
Zhi Wang ${ }^{\mathrm{a}, \mathrm{b} *}$, Zhifeng $\mathrm{Li}^{\mathrm{b}, \mathrm{c}}$, Yonglin Shen ${ }^{\mathrm{b}, \mathrm{c}}$, Lixin $\mathrm{Wu}^{\mathrm{b}, \mathrm{c}}$ Huiying $\mathrm{Li}^{\mathrm{d}}$ \\ ${ }^{a}$ College of Resources and Civil Engineering, Northeastern University, Shenyang 110819, P. R. China. \\ ${ }^{\mathrm{b}}$ Academy of Disaster Reduction and Emergency Management, Ministry of Civil Affairs, \\ Ministry of Education (Beijing Normal University), Beijing, 100875, P.R. China \\ ${ }^{\mathrm{c}}$ Key Laboratory of Environment Change \& Natural Disaster of MOE, Beijing Normal University, Beijing 100875, P. \\ R. China \\ ${ }^{\mathrm{d}}$ College of Computer Science and Technology, Jilin University, Changchun 130012, P. R. China
}

Special Sessions: URSI and ISPRS: Disaster Management

KEY WORDS: Event-driven, Comprehensive Evaluation, Natural Disaster assessment, Flood, Earthquake

\begin{abstract}
:
The Chinese event-driven observations and disaster assessment system is established so as to make information related to environmental risk and vulnerability easily accessible to decision-makers through this centralized platform. At 7:49 AM on April 14, 2010, an earthquake of 7.1 magnitude collapsed buildings in Yushu County, Yushu Tibetan Autonomous Prefecture in Qinghai Province. For emergence response, we presented a method for generating seismic intensity map based on seismological mechanism solutions. The disaster assessment system automatically drew the distribution map of affected population 1 hour after the Yushu earthquake. In the case of distribution map of affected population, we made the judgment that the Gyêgu town maybe the worst hit town in the Yushu earthquake because it is not only near the epicenter, but also the capital of Yushu Tibetan Autonomous Prefecture. Then event-driven observations are taken on Gyêgu town. Referring to usable data, the chains of rapid assessment on earthquake disaster were analyzed, and different models were established for assessing affected population, damaged houses and lifelines and comprehensive earthquake loss evaluation.
\end{abstract}

\section{INTRODUCTION}

China suffers severe natural disasters which cause tremendous damage, economic loss and pose threat to people and their properties every year. Rapid response to the onset of natural disaster, such as earthquake, flood [1-2], landslide and so on, allows for the early assessment of hazard and risk. These natural disasters can be monitored by linking notifications of activity via event-driven remote sensing from ground-based and space based systems [3].

\section{EVENT-DRIVEN OBSERVATIONS OF NATURAL DISASTER}

As shown in Table 1, HJ-1A and 1B (Huan Jing = Environment) satellites are small Chinese earth observation satellites. The satellite constellation is composed of a number of small satellites, the ground system and the application system. They will provide all-weather imagery. The Huan Jing constellation consists of two small optical satellites, the HJ-1A and the HJ$1 \mathrm{~B}$, and one radar satellite the HJ-1C. The payload instrument on board includes a CCD camera (both), a hyper-spectral camera (HJ-1A) or an infrared camera (HJ-1B).

\begin{tabular}{|c|c|c|c|}
\hline Satellite & Payload & $\begin{array}{c}\text { Band } \\
\text { no. }\end{array}$ & $\begin{array}{c}\text { Spectral range } \\
(\mu \mathrm{m})\end{array}$ \\
\hline \multirow{5}{*}{ HJ-1A } & \multirow{4}{*}{ CCD Camera } & 1 & $0.43 \sim 0.52$ \\
\hline & & 2 & $0.52 \sim 0.60$ \\
\hline & & 3 & $0.63 \sim 0.69$ \\
\hline & & 4 & $0.76 \sim 0.9$ \\
\hline & $\begin{array}{l}\text { Hyperspectral } \\
\text { Imager }\end{array}$ & - & $\begin{array}{c}0.45 \sim 0.95 \\
(110-128 \text { bands })\end{array}$ \\
\hline \multirow{8}{*}{ HJ-1B } & \multirow{4}{*}{ CCD Camera } & 1 & $0.43-0.52$ \\
\hline & & 2 & $0.52-0.60$ \\
\hline & & 3 & $0.63-0.69$ \\
\hline & & 4 & $0.76-0.9$ \\
\hline & \multirow{4}{*}{$\begin{array}{c}\text { Infrared } \\
\text { Multispectral } \\
\text { Camera }\end{array}$} & 5 & $0.75-1.10$ \\
\hline & & 6 & $1.55-1.75$ \\
\hline & & 7 & $3.50-3.90$ \\
\hline & & 8 & $10.5-12.5$ \\
\hline $\mathrm{HJ}-1 \mathrm{C}$ & $\begin{array}{c}\text { Synthetic Aperture } \\
\text { Radar } \\
\text { (SAR) } \\
\end{array}$ & 1 & $\mathrm{~S}$ band \\
\hline
\end{tabular}

\footnotetext{
* Corresponding author: Zhi Wang: wangzhi@mail.neu.edu.cn
} 


\begin{tabular}{|c|c|c|c|c|c|}
\hline Satellite & \begin{tabular}{|c}
$\begin{array}{c}\text { Spatial } \\
\text { resolution } \\
(\mathrm{m})\end{array}$ \\
\end{tabular} & $\begin{array}{l}\text { Swath } \\
\text { width } \\
(\mathrm{km})\end{array}$ & $\begin{array}{c}\text { Side- } \\
\text { looking } \\
\text { ability } \\
\end{array}$ & $\begin{array}{c}\text { Repetition } \\
\text { cycle } \\
\text { (days) }\end{array}$ & \begin{tabular}{|c|} 
Data \\
transmission \\
rate (Mbps) \\
\end{tabular} \\
\hline \multirow{5}{*}{ HJ-1A } & 30 & \multirow{4}{*}{700} & & \multirow{4}{*}{4} & \multirow{5}{*}{120} \\
\hline & 30 & & & & \\
\hline & 30 & & & & \\
\hline & 30 & & & & \\
\hline & 100 & 50 & $\pm 30^{\circ}$ & 4 & \\
\hline \multirow{6}{*}{ HJ-1B } & 30 & \multirow{4}{*}{700} & & \multirow{4}{*}{4} & \multirow{6}{*}{60} \\
\hline & 30 & & & & \\
\hline & 30 & & & & \\
\hline & 30 & & & & \\
\hline & 150 & \multirow{2}{*}{720} & & \multirow{2}{*}{4} & \\
\hline & 300 & & & & \\
\hline $\mathrm{HJ}-1 \mathrm{C}$ & $\begin{array}{c}20 \mathrm{~m}(4 \\
\text { looks, } \\
\text { scan } \\
\text { mode }) \\
5 \mathrm{~m}(\text { single } \\
\text { look, strip } \\
\text { mode })\end{array}$ & $\begin{array}{c}100(\text { scan } \\
\text { mode }) \\
40(\text { strip } \\
\text { mode })\end{array}$ & $\begin{array}{l}31^{\circ}- \\
44.5^{\circ}\end{array}$ & 4 & $\begin{array}{c}160 * 2 \\
(8: 3 \\
\text { compressio } \\
\text { n) }\end{array}$ \\
\hline
\end{tabular}

Table 1.Technical specification of payloads of $\mathrm{HJ}-1 \mathrm{~A} / 1 \mathrm{~B}$

As shown in Figure 1, the event-driven observation monitors natural disaster around the China. The steps include:

1. Sensor instruments [e.g., CCD cameras, a hyperspectral camera and an infrared camera on the HJ-1A and $1 \mathrm{~B}$ spacecraft] acquire low-resolution $(30 \sim 300$ meters per pixel) data.

2. Data from sensor instruments are downlinked and automatically processed to detect abnormal information of natural disaster.

3. Event notification is entered into an automated operations planner that generates sequences of commands to be executed by spacecraft and instruments.

4. Aircrafts with onboard sensor instruments are tasked to acquire high resolution data and field measurements are implemented.

5. New science data is rapidly downlinked and transmitted to scientists.

6. Disaster evaluation system produces the natural disaster assessment products for decision-making support.

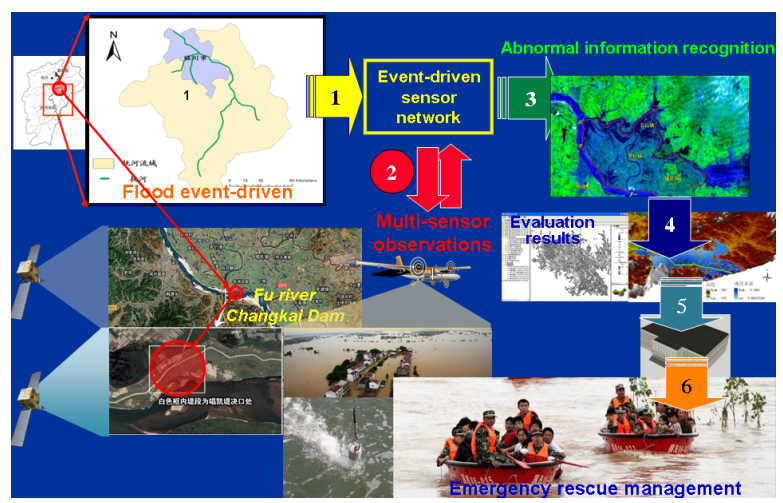

Figure 1: Event-driven observations in Fu river flood (June, 2010), Jiangxi province, P. R. China

\section{GENERAL ARCHITECTURE OF DISASTER ASSESSMENT SYSTEM}

Natural disasters pose serious threats to life and infrastructure, as well as to the economic and social fabrics that sustain nations Disaster management is the discipline of dealing with and avoiding risks, involves preparing for disaster before it occurs, disaster response, and supporting, and rebuilding society after natural or human-made disasters have occurred. Disaster management poses significant challenges for data collection, data management, discovery, translation, integration, visualization and communication. Evaluation is an important portion of disaster management. According to the service requirement, its principal target includes:

1. Disaster loss rapid evaluation: According to disaster rescue demand, using disaster related data of satellite, observed and reported to evaluate the affected people, afflicted crops, damaged houses and lifelines rapidly.

2. Comprehensive disaster evaluation: During stability process of disaster or at end of disaster, based on the result of rapid loss assessment, using spatial information technology to evaluate the losses comprehensively [4], including economic loss evaluation, disaster grade evaluation and disaster rescue requirement evaluation [5].

According to the above targets, the disaster assessment system divides into two sub systems: rapid disaster loss evaluation system and comprehensive disaster evaluation system (as shown in Figure 2). Figure 3 shows the graphical user interface of the disaster assessment system.

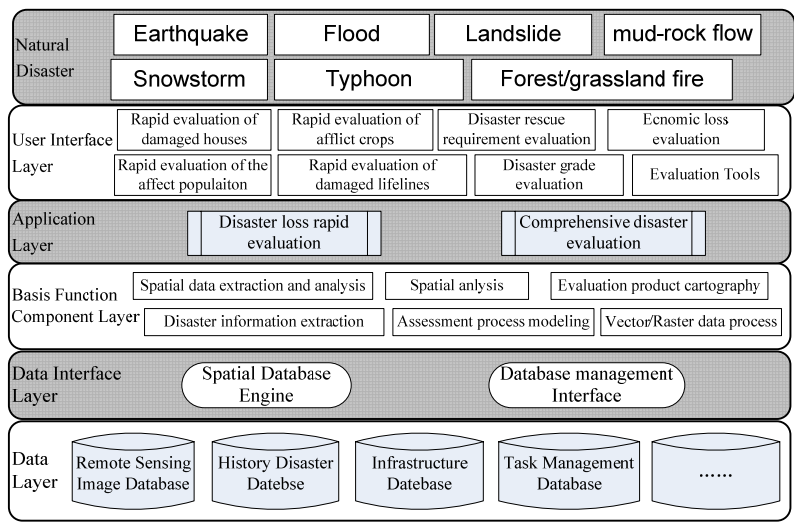

Figure 2: The general architecture and composition of disaster assessment system

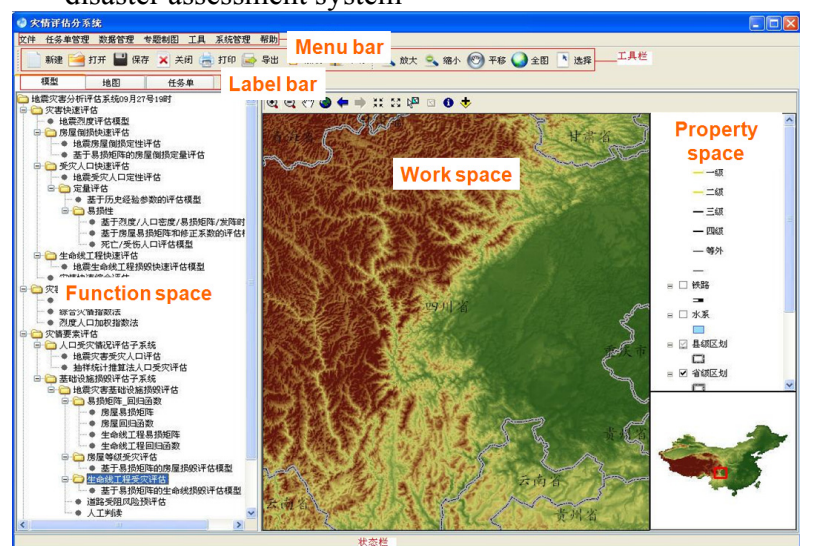

Figure 3: Graphical user interface of the disaster assessment system 


\section{APPLICATION: YUSHU EARTHQUAKE CASE STUDY}

Based on the assessment system designed above, Yushu earthquake was taken being a study case. On April 14th, 2010, a large earthquake $(M s=7.1)$ shocked the Yushu county in the Qinghai Province at western China. It caused severe damages and fatalities. For emergence response, the rapid disaster loss evaluation system firstly summarized current evaluation models for rapid seismic intensity. We presented a method for generating seismic intensity map based on seismological mechanism solutions. As shown in Figure 3, the disaster assessment system automatically drew the distribution map of affected population one hour after the Yushu earthquake. The Figure 4 shows the accurate distribution map of affected population twelve hours after the Yushu earthquake according to the seismic intensity map of China Earthquake Administration.

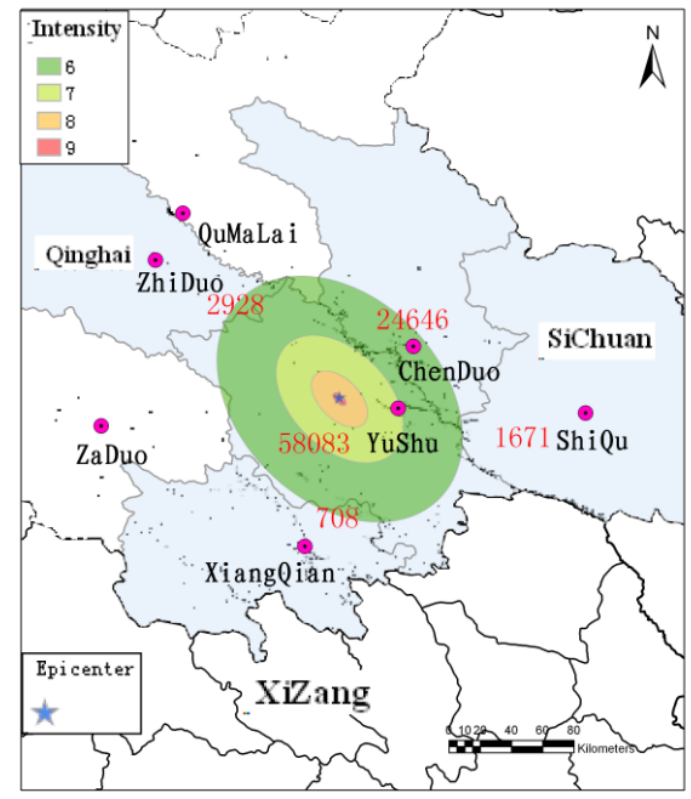

Figure 3: the distribution map of affected population based on rapidly assessed seismic intensity

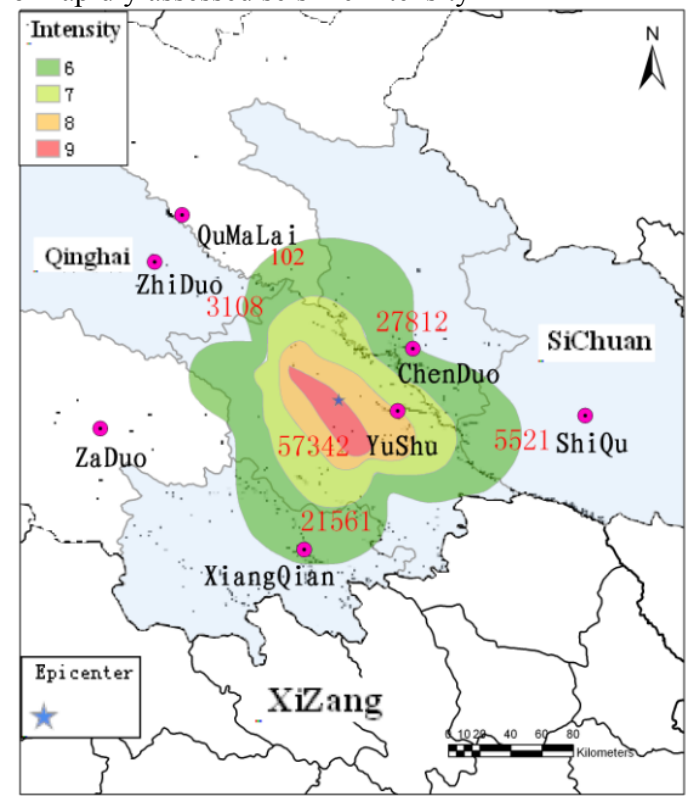

Figure 4: the accurate distribution map of affected population
In the case of distribution map of affected population, we made the judgement that the Gyêgu town maybe the worst hit town in the Yushu earthquake because it is not only near the epicenter, but also the capital of Yushu Tibetan Autonomous Prefecture. Gyêgu town locates in the southern part of Qinghai Province, close to the provincial border with Tibet Autonomous Region, and more than 90 percent of its population of about 100,000 is ethnic Tibetans.

\subsection{Data Set}

Four main data sets are used in the study:

1. Remote Sensing image, 2007, the image obtained from Google Earth which captured on Nov., 2007;

2. Seismic Intensity Map and Fault Trace (as shown in Figure 5), supported by the National Earthquake Bureau, China;

3. ASTER 30m DEM, ASTER (Advanced Spaceborne Thermal Emission and Reflection Radiometer) is an imaging instrument flying on Terra, a satellite launched in December 1999 as part of NASA's Earth Observing System (EOS) [9]. ASTER offers Global Digital Elevation Model (GDEM) to the worldwide, and 30 meter resolution of Gyêgu is available;

4. Remote Sensing image (as shown in Figure 6 and Figure 7), 2004 (pre-event) \& 2010 (post-event), two panchromatic images of QuickBird satellites covering Gyêgu town were acquired on 2004 and 2010 with 0.6 $\mathrm{m}$ ground resolutions.

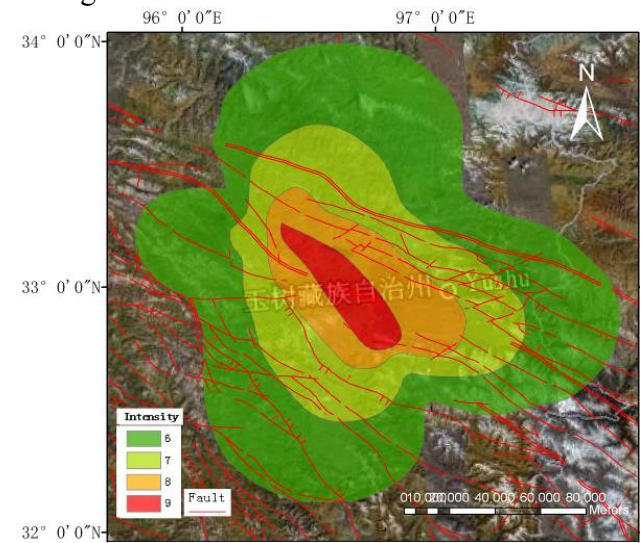

Figure 5 Fault trace and seismic intensity map of Yushu Earthquake

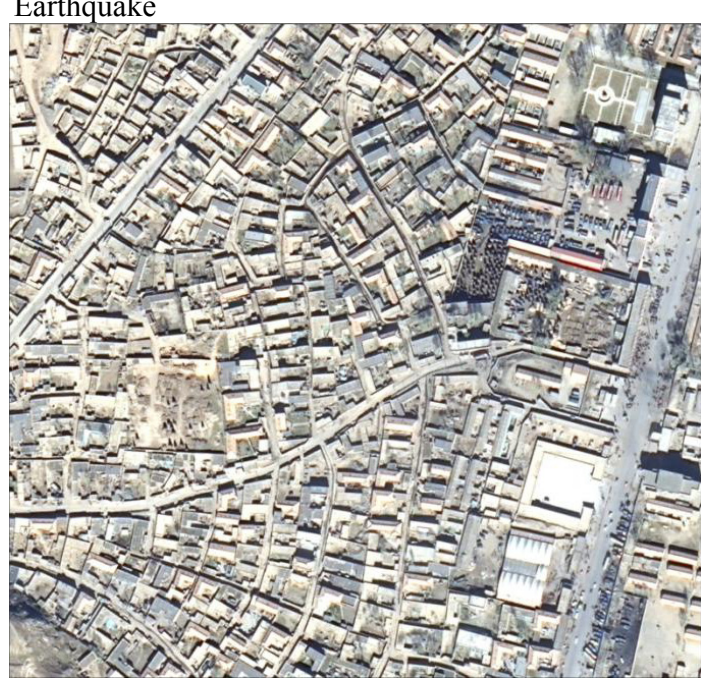

Figure 5: pre-earthquake airborne image of Gyêgu town 


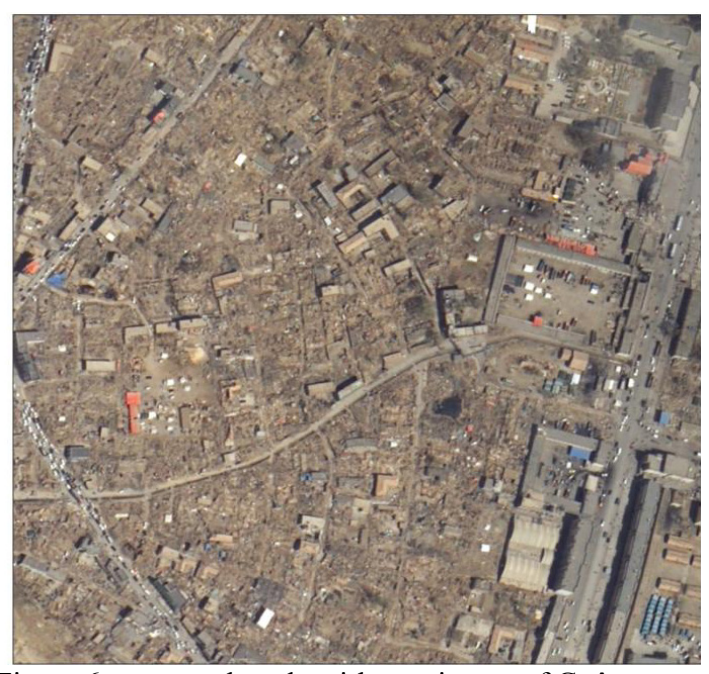

Figure 6: post-earthquake airborne image of Gyêgu town

Referring to usable data, the chains of rapid assessment [7] on earthquake disaster were analyzed, and different models were established for assessing affected population, damaged houses and lifelines and comprehensive earthquake loss evaluation.

Data collection using satellite remote sensing offers a variety of advantages compared to other forms of data acquisition, especially in disaster environments cause it serves as a large archive of historical data. Remote sensing image provides very useful information which carried out an operation of postearthquake emergency building inspections more efficiently, for a wide range of scales. In the study, multi-resource data was used, and the framework illustrated in Figure 7. For information extraction, modeling and 3D visualization efficiently and effectively, tools of ArcGIS Desktop 9.3 (ArcMap, ArcScene, etc) and Google SketchUp 6.0 were used.

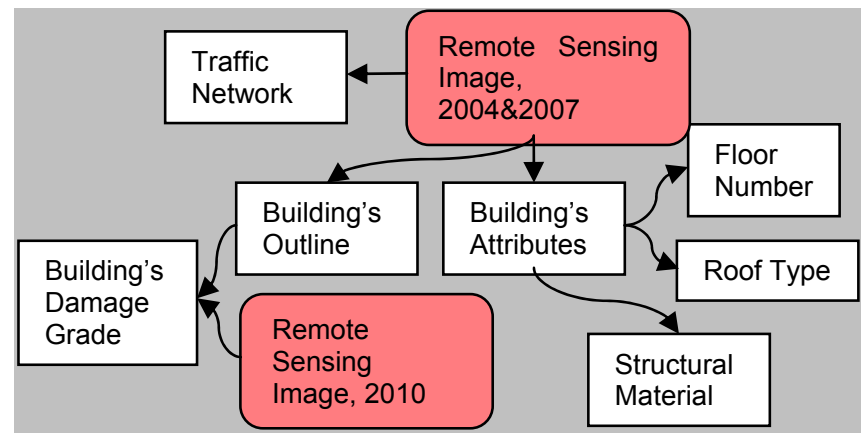

Figure 7 Workflow of information extraction

Data processing and information extraction from remote sensing images are the primary procedure for disaster management. As shown in Figure 7, traffic network, building's attributes (structural materials, floor number and roof types) and building's damage grades were extracted from pre- and postevent remote sensing images. More details presented as follows:

\subsection{Building's outlines}

Building is the main element to form a city and its outline is the fundament of urban mapping and 3D building modeling. As shown in Figure 8, Building's outlines could extract from remote sensing images by commercial software like ENVI,
ERDAS Imagine, eCongnition, etc, automatically or extract manually by interaction.

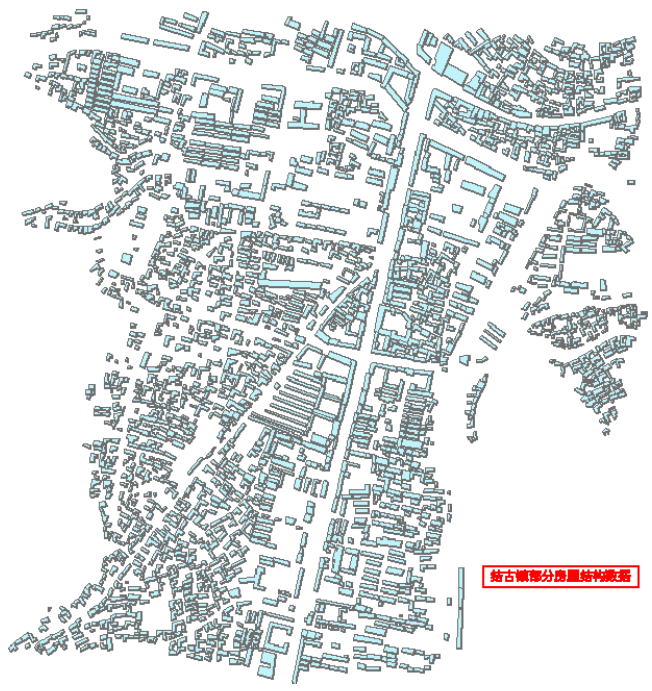

Figure 8: Building structures in Gyêgu town

\subsection{Building's floor number}

In the study, the building's floor number counts above ground in the building. The building heights could be roughly delimited from the shadows in the high-resolution remote sensing image. Under the same sun elevation and azimuthal angle condition, building's floor number is proportional to its shadow length in the remote sensing image. Measuring the shadow length of a building whose floor number already known as the standard, building' floor number of whole region can be counted out.

\subsection{Building's structural materials}

As known, structural materials affect the damage grade of buildings during a destructive earthquake. The Common structural materials in the study area are timber (Figure 9a.), masonry (Figure 9b.), concrete (Figure 9c.), reinforced concrete (Figure 9d.) and steel (Figure 9e.). A majority of the buildings have been built as timber and masonry in the affected region and a large number of such buildings were heavily damaged or collapsed. Building's structural materials can be recognized with its size, roof and façade texture, floor number, roof type, etc. Normally, the timber, masonry and concrete buildings are relatively lower than reinforced concrete buildings and most of them are one-to-three-storey. Most of masonry and timber buildings are gable roof, while the concrete and reinforced concrete buildings are flat roof. The steel structures could only be found in specific purpose like factory, carport, etc.
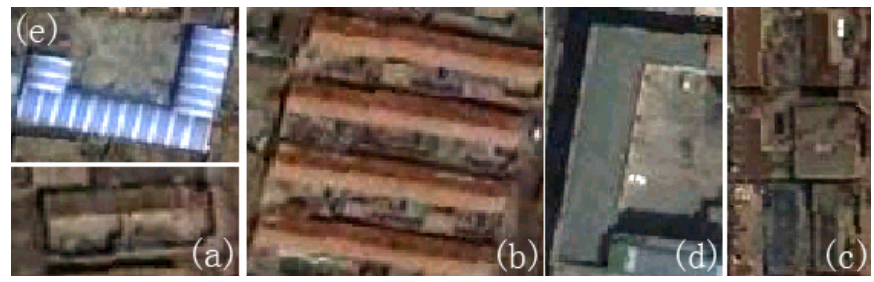

Figure 9 Different types of building's structural materials

\subsection{Building's roof types}

A roof is the covering on the uppermost part of a building and roof types can be distinguished clearly from the high-resolution remote sensing image with the gray value. In the study area, the 
most common are flat (Figure 10a), gable (Figure 10b) and hip roofs (Figure 10c).
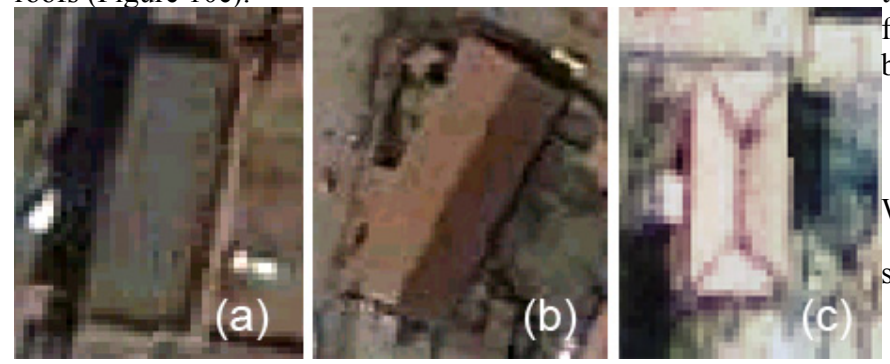

Figure 10 Different types of building's roof

\subsection{Building's damage grades}

For identify building's damage grades, the extracted building's outlines was registered on the post-event remote sensing image. Then visual inspection of building's damage grades was conducted. Four damage grades were concerned, slightly damage (Figure 11a), moderate damage (Figure 11b), heavy damage (Figure 11c) and destruction (Figure 11d).

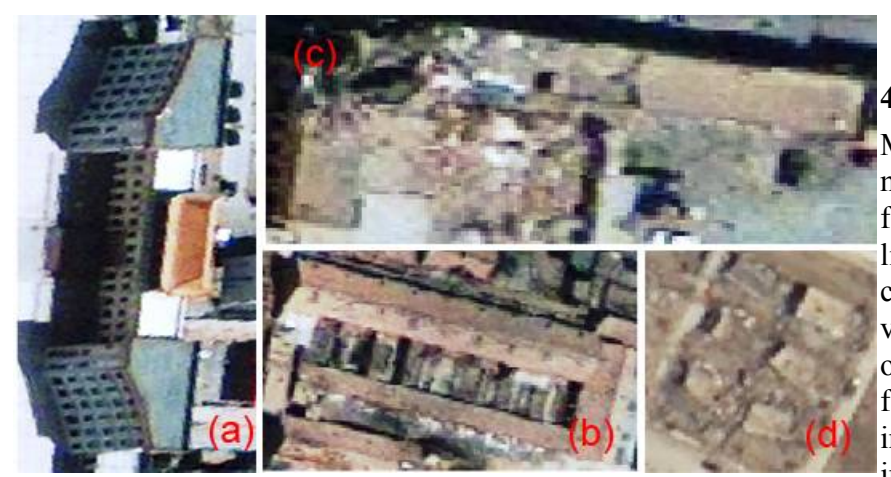

Figure 11 Different types of building's damage grades

\subsection{Traffic network}

Traffic network is the fundamental geographic data which could further used to provide complete road status and damage assessment information to emergency operations. In the study area, roads are divided into arterial road and secondary road, different road type was digitized in different layer with ArcMap.

\subsection{Modeling of Buildings}

3D models allowing decision makers to be more quickly recognizing and understanding changes in elevation, pattern and features, so they are used for the visualization of disaster risk indexes and vulnerabilities to support disaster decision processes. As described above, 2D vector building outlines, building's roof type, structure material, floor number and damage grades could be used to construct 3D textured buildings. With the tool of Google SketchUP 6.0 (which enables user to quickly create very realistic models of buildings and other $3 \mathrm{D}$ objects), the models were conducted efficiently. To construct textured 3D seismic buildings, building's outlines were firstly exported from ArcMap with a geographic reference, models were created in SkethchUP next, and then models were exported into an ESRI Personal Geodatabase that can be opened in ArcScene. For modeling, we firstly extrude building polygons by a height value (which calculated with Formula 1.) to create realistic building shapes; secondly, we roof was construct with its roof type and building's facades were textured different with structural materials; thirdly, building's roof was colored different with damage grades, as shown in Figure 8.
Building floor is the unit object for desired 3D urban model. In the study area, maximum floor number is 12 and assumed floorfloor height is $3.0 \mathrm{~m}$. the formula for calculating the height of a building:

$$
H_{b}=N_{s} \times H_{f 2 f}
$$

Where, $H_{b}$ is the height of building, $N_{s}$ is the number of stories and $H_{f 2 f}$ is the floor-to-floor height.

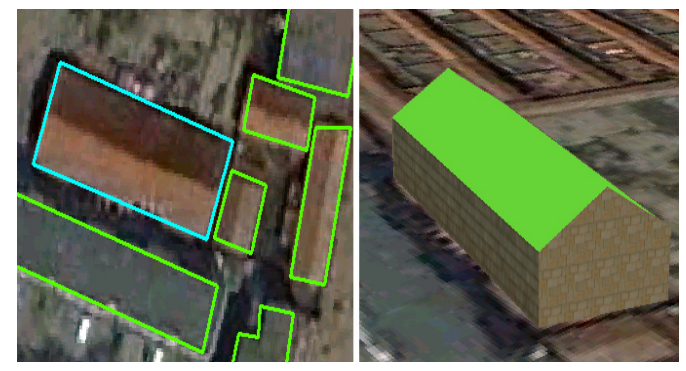

Figure 1. Example of reconstruction of buildings

\subsection{Scene Rendering and 3D Visualization}

Multi-scale 3D visualization is required for disaster management due to the need for different details of information for different kinds of decisions. For coarse scale, seismic data like fault trace and seismic intensity map which are largest close to the earthquake are the primary data source for $3 \mathrm{D}$ visualization, because they concern where the earthquake occurs, where is the worst-hit area, where the fault trace, etc. so, for 3D visualization of coarse scale, data of fault trace seismic intensity map, DEM (Digital Elevation Model), remote sensing images should be rendered in the same reference frame, as shown in Figure 6. While, for fine scale, building's attributes are the primary data source for $3 \mathrm{D}$ visualization, and the most concerned thing for decision makers is which building damaged and how to implement survivors rescue. For this purpose, data of traffic network, 3D building models, building's damage grade, DEM, remote sensing images were incorporated into a GIS environment for decision-making and further disaster management. The result is visualized using the ArcScene which enables to overlay many layers of data in a $3 \mathrm{D}$ environment shown in Figure 12.

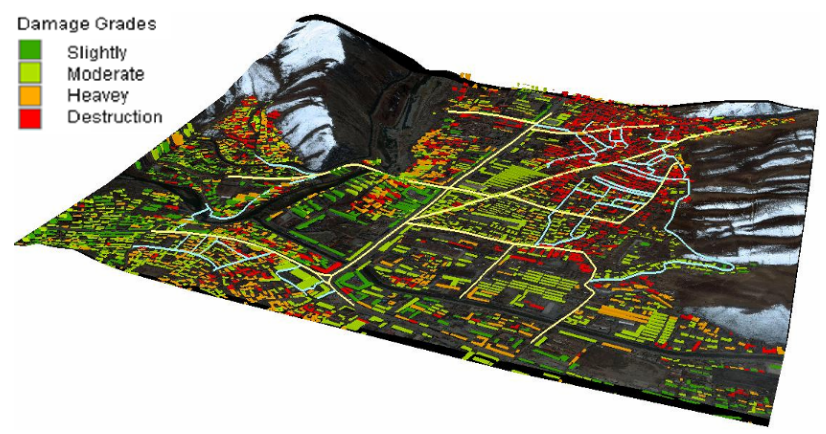

Figure 12: The distribution of seismic damaged buildings in Gyêgu town in Yushu earthquake

Figure 12 shows the comprehensive evaluation results of seismic damaged buildings in the Gyêgu town by using the aerial images and damaged building evaluation models. The Yushu earthquake causing tremendous damage in the urban areas of Gyêgu town, Qamdo, etc, killing about 3000 people, 
injuring about 12000 people and damaging thousands of buildings [8].

\section{SUMMARY}

The main purpose of this paper is to describe the Chinese eventdriven observation and comprehensive disaster evaluation system for disaster management. Models and methods of multidisasters comprehensive evaluation, including general system function design and system architecture design were proposed. At last, taking Yushu earthquake being a case, earthquake disaster comprehensive evaluation system is analyzed in details and the result proved that it has a good application effects.

\section{REFERENCES}

Charles S.F., Neil B., Hope S. et al. "HAZUS-MH flood loss estimation methodology. I: Overview and flood hazard characterization". Nature Hazards Review, Vol 7, pp.60-71, 2006.

Dushmanta Dutta, Srikantha Herath, Katumi Musiake. "A mathematical model for flood loss estimation". Journal of Hydrology, Vol 277, pp.24-49, 2003.

A. G. DAVIES, S. CHIEN, R. WRIGHT, et al. "Sensor Web Enables Rapid Response to Volcanic Activity". Eos, Vol. 87, No. 1, 3 January 2006.

Peijun Shi. "Theory and practice of disaster study". Journal of Nanjing University, Vol: Special issue of nature disasters, pp.37-42, 1991.

Peijun Shi. "Theory on disaster science and disaster dynamics". Journal of Nature Disasters, Vol 11, pp.1-9, Aug.2002.

Guo HuaDong, Zhang Bing, Lei LiPing, Zhang Li, Chen Yu. Spatial distribution and inducement of collapsed buildings in Yushu earthquake based on remote sensing analysis Science in China Series D: Earth Sciences, v 53, n 6, p 794-6, June 2010

M. Erdik, K. Sesetyan, M.B. Demircioglu, et al. "Rapid earthquake loss assessment after damaging earthquakes". Soil Dynamics and Earthquake Engineering, Vol. 31, pp.247-266, 2011.

Shen Yonglin, Wu Lixin, Li Zhifeng, Li Xiaojing. "3D Visualization of Seismic Buildings in Yushu Earthquake for Disaster Management”. Multimedia Technology (ICMT), 29-31 Oct. 2010.

\section{ACKNOWLEDGEMENTS}

Work described in this paper was funded by 973 Program (2011CB707102); National Natural Science Foundation of China (40901220, 41001302); Fok Ying Tong Education Foundation (122025); Fundamental Research Funds for the Central University (N100401009, 105565GK). 